\title{
Medical ethics: Debates, dilemmas and decisions
}

\author{
Joanne Embree MD FRCPC, University of Manitoba, Winnipeg, Manitoba
}

$\mathrm{D}$ uring the past five to 10 years, medical ethics has become a high profile and popular medical subspecialty. This has resulted in considerable interest and debate concerning medical ethics in the lay press as well as in medical journals. At every medical school in Canada, numerous rounds each year are devoted to this subject. Allegations of unethical behaviour on the part of physicians, medical school professors, hospital boards, university administration officials and the pharmaceutical industry regularly result in front page headlines and prime time television news features. On occasion, these allegations are related to some aspect of infectious disease.

Based on a search of the World Wide Web in early March of this year, there appear to be 3991 web sites concerned with medical ethics in relation to a variety of infectious diseases. Of these, nearly one-third (1696) concerned the ethical issues surrounding routine vaccine administration to children or the military. This is not a major surprise. In contrast, although there were 32,499 citations on MEDLINE related to medical ethics, there were only 645 articles concerning infectious disease. These mostly involved statements and opinions related to HIV/AIDS research and treatment opportunities in developing countries. There were 118 medical citations related to the ethical issues surrounding vaccines, primarily concerning the anticipated HIV vaccine trials. The topics found on the various lay web sites included these issues but mainly explored opinions concerning a vast array of other subjects. It would seem that the debate on these topics in the lay press far exceeds that among the medical profession. Are the lay press talking too much? Are we talking too little?

There are a large number of ethical considerations that we deal with on a day-to-day basis as we see patients, conduct our research, and fulfill our administrative obligations to the hospitals, clinics, universities and/or government agencies to which we are affiliated. Examples of these considerations in- clude such issues as deciding whether to recommend an invasive procedure, such as a lung biopsy, to determine the infecting agent when the patient has a terminal disease; deciding what information to include in a study consent form; or deciding whether to vaccinate routinely a group of individuals at higher risk than the general public for a particular infection. We also have to manage our complex relationships with the pharmaceutical industry appropriately. When are we too closely involved to be objective in our recommendations? We also have many potential conflicts of interest when dealing with some government agencies that play major roles in our incomes.

Depending upon the circumstances, any of these situations could result in the identification of major ethical dilemmas and heated public debates. However, they rarely do (for which most of us are profoundly grateful). In general, we tend to discuss ethical issues with those individuals directly involved with an expectation that, at the end of the conversation, a correct decision will be made and implemented. We, as a profession, rarely initiate public debate. It is not something that we have been trained to do. We are not trial lawyers or professional politicians. We tend to try to avoid the type of public spotlight that focuses on our ethical views or behaviour, particularly as we watch other colleagues suffer in it. Should we change our attitude?

A great deal of good does ultimately come from identifying ethical problems, debating the issues and viewpoints of those involved, and arriving at a decision about how to deal with them. For those of us who have practiced or conducted research in the AIDS field, our involvement in the ethical debates surrounding the rights of those affected with HIV has come to be accepted and appreciated. This explains, in part, the preponderance of articles in the medical literature related to ethical issues associated with AIDS. Our involvement is im- 
portant in debates concerning ethical issues related to other infectious diseases. We have a vested interest in seeing that ethical problems are solved. To make correct decisions, all relevant facts and viewpoints need to be considered and we can bring to these debates our unique knowledge of the disease processes involved and what the consequences of some actions may be. If we do not take on a role in medical ethics, wrong decisions may be made or, worse yet, no decisions may be made at all. We do need to express and debate our opinions in the medical literature. We also need to arrive at a consensus concerning those ethical issues that are important to us. We are generally willing to set practice guidelines concerning the investigation of and treatment options for infectious diseases. Setting practice standards and guidelines for ethical issues is just as important. Finally, we need to take the time to develop teaching modules for medical students and residents to teach them to examine the ethical problems related to infectious diseases that they might be confronted with in the future. In this way, we may avoid some of the mistakes that were made in the past. 


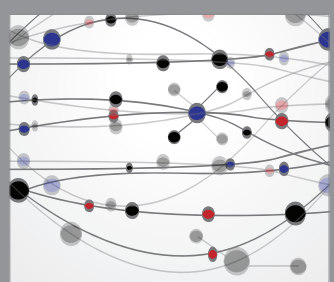

The Scientific World Journal
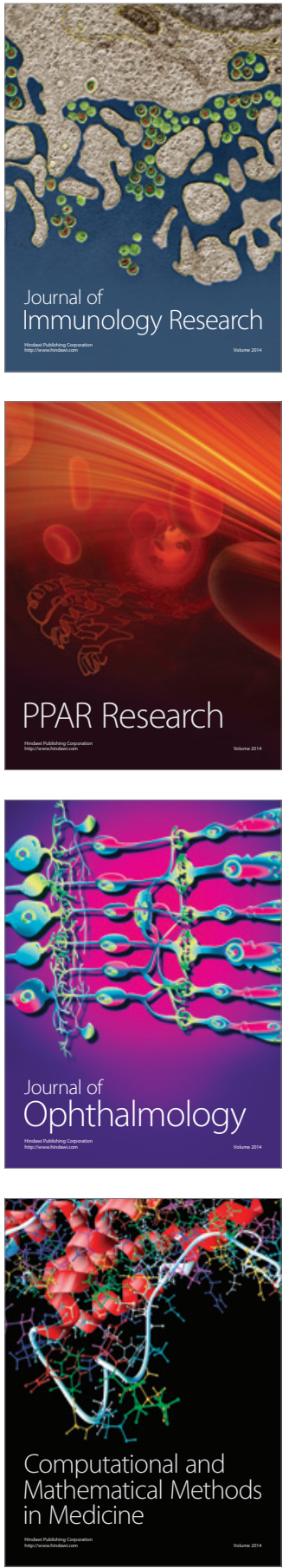

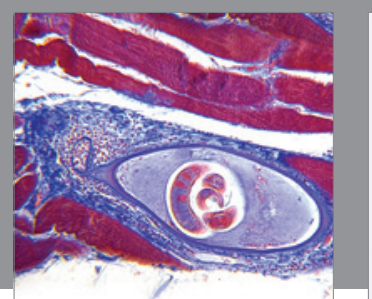

Gastroenterology Research and Practice

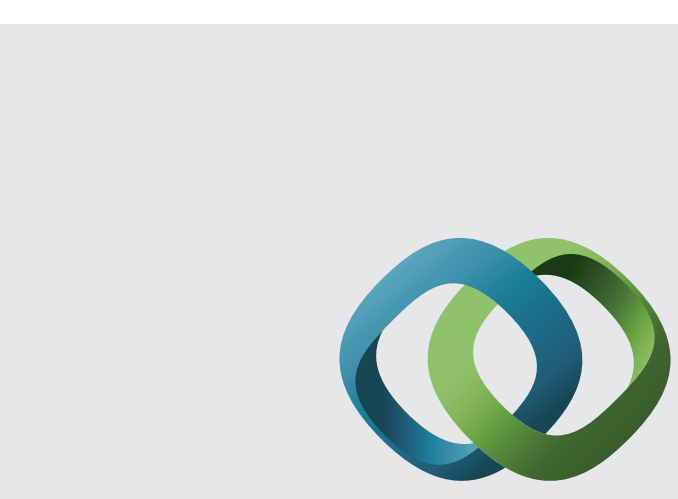

\section{Hindawi}

Submit your manuscripts at

http://www.hindawi.com
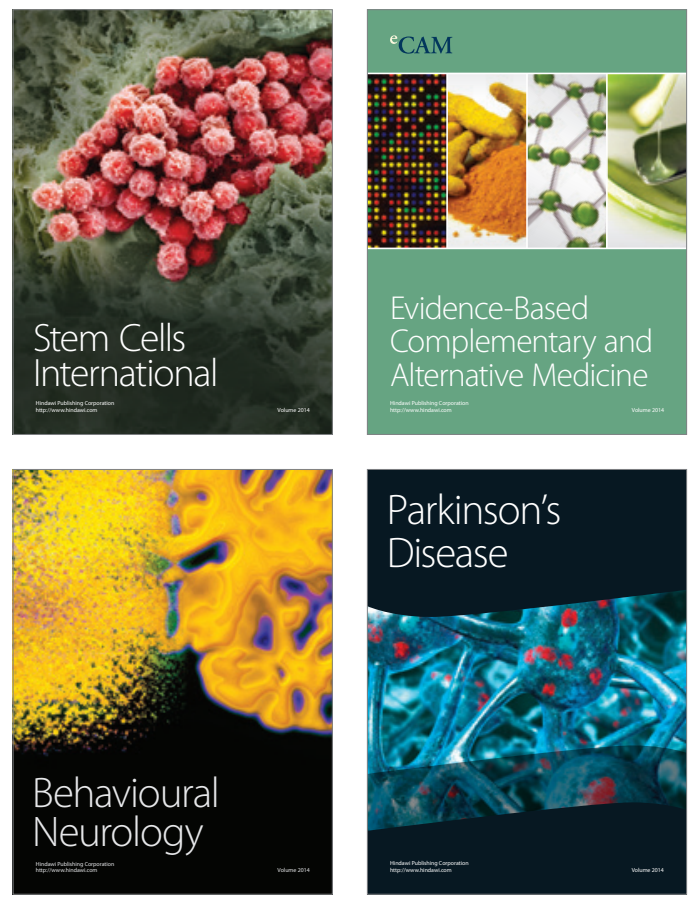
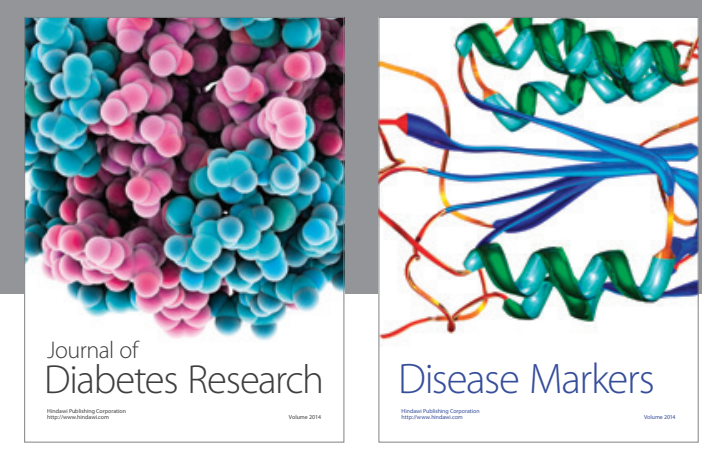

Disease Markers
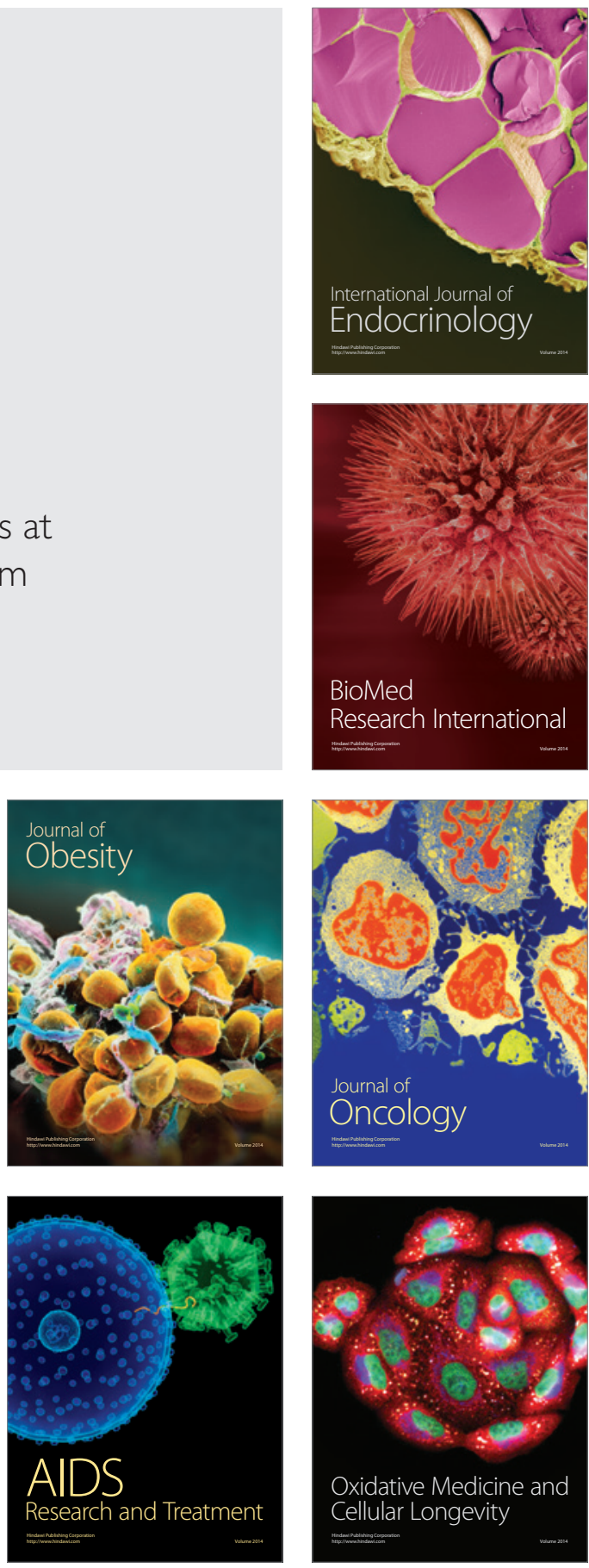